\title{
11C-choline PET/CT and whole-body MRI including diffusion- weighted imaging for patients with recurrent prostate cancer
}

\author{
Hinrich Wieder ${ }^{1,2}$, Ambros J. Beer ${ }^{1,7}$, Konstantin Holzapfel ${ }^{3}$, Martin Henninger ${ }^{1}$, \\ Tobias Maurer ${ }^{4}$, Sarah Schwarzenboeck ${ }^{5}$, Ernst J. Rummeny ${ }^{3}$, Matthias Eiber ${ }^{1, *}$ \\ and Jens Stollfuss $\mathbf{S}^{3,6, *}$ \\ ${ }^{1}$ Department of Nuclear Medicine, Klinikum rechts der Isar, Technische Universität München, Munich, Germany \\ ${ }^{2}$ Centre for Radiology and Nuclear Medicine, Grevenbroich, Germany \\ 3 Institute for Diagnostic and Interventional Radiology, Klinikum rechts der Isar, Technische Universität München, Munich, \\ Germany \\ ${ }^{4}$ Department of Urology, Klinikum rechts der Isar, Technische Universität München, Munich, Germany \\ ${ }^{5}$ Department of Nuclear Medicine, Universitätsmedizin Rostock, Rostock, Germany \\ ${ }^{6}$ Department of Radiology and Nuclear Medicine, Klinikum Memmingen, Memmingen, Germany \\ 7 Department of Nuclear Medicine, Ulm University, Ulm, Germany \\ * These authors have contributed equally to this manuscript \\ Correspondence to: Hinrich Wieder, email: h@wieder.de
}

Keywords: prostate cancer, recurrence, 11C-choline, PET/CT, MRI

Received: November 18, $2016 \quad$ Accepted: March 06, $2017 \quad$ Published: March 15, 2017

Copyright: Wieder et al. This is an open-access article distributed under the terms of the Creative Commons Attribution License 3.0 (CC BY

3.0), which permits unrestricted use, distribution, and reproduction in any medium, provided the original author and source are credited.

\section{ABSTRACT}

Purpose: To compare the detection efficacy of 11C-choline positron emission tomography and computed tomography (PET/CT) with whole-body magnetic resonance imaging (MRI) including diffusion-weighted imaging (DWI) in patients with suspected recurrent prostate cancer.

Materials and Methods: Fifty-seven patients (mean age 68, range 54-80 years) underwent 11C-choline PET/CT and MRI using T1-weighted (T1w), short-tau inversion recovery (STIR), and DWI. Two readers visually rated suspicious lesions on a 5-point scale in $\mathbf{2 0}$ different regions. Clinical follow-up and histopathology served as the standard of reference (SOR).

Results: Fifty patients (mean PSA 29.9, range 1.0-670 $\mathrm{ng} / \mathrm{mL}$ ) had at least one positive lesion according to the SOR. Twenty-four patients had local recurrence (LR), 27 had lymph node (LN) involvement, and 22 had bone metastases. The overall detection rates for PET/CT and MRI on a patient basis were $94 \%$ and $88 \%$, respectively $(p=0.07)$. The PSA level ( $>2 \mathrm{ng} / \mathrm{mL}$ vs $\leq 2 \mathrm{ng} / \mathrm{mL})$ significantly influenced the overall performance of PET/CT $(p=0.003)$ and MRI $(p=0.03)$. PET/CT was significantly superior to MRI in detecting $\operatorname{LR}(p=0.03)$ and bone metastasis $(p=0.02)$. We found no difference with respect to the detection of $L N$ metastasis $(p=0.65)$.

Conclusion: 11C-choline PET/CT was superior in the detection of local recurrence and bone metastasis on a regional basis. Whole-body MRI including DWI showed similar diagnostic accuracy only for detecting lymph node metastases. Compared with 11C-choline PET/CT, therefore, whole-body MRI including DWI cannot serve as alternative imaging modality for restaging prostate cancer.

\section{INTRODUCTION}

Prostate cancer is the third most common cause of death from cancer in men (9.5\%) in Europe and is associated with a high rate of recurrence [1]. After primary treatment, relapse occurs in $20-30 \%$ of patients within 
10 years of prostatectomy [2] and in up to 53\% within 5 years of external-beam radiotherapy [3]. The diagnostic sensitivity of conventional imaging in the setting of PSA recurrence is often disappointing.

Positron emission tomography (PET) using $11 \mathrm{C}$-choline has been shown to be promising in both staging and follow-up of patients with prostate cancer $[4,5]$. PET is usually performed in combination with computed tomography (PET/CT), which provides a comprehensive anatomical and molecular whole-body survey in a single imaging session [6]. In the case of recurrent prostate cancer, combining the two modalities facilitates the anatomical localization of PET-positive findings [7]. However, C11-cholin fails to identify a positive lesion in a substantial number of cases, especially in patients with PSA values lower than $2 \mathrm{ng} / \mathrm{mL}$. However, initial PET studies using Prostate-specific membrane antigen ligands (e.g. 68Ga-PSMA HBED-CC) recently achieved superior detection rates compared to $11 \mathrm{C}$-choline even at low PSA [8].

Whole-body magnetic resonance imaging (MRI) became possible with the development of parallel imaging and high-gradient amplitudes [9, 10]. High spatial resolution diffusion-weighted imaging (DWI) has also been introduced [11]. This technique offers high lesion-to-background contrast and has been suggested as an adjunct to detect primary malignancies and metastases in oncology patients [12-14]. DWI may also be used to characterize lesions by quantitative apparent diffusion coefficient (ADC) values. ADC values have been regarded as a potential imaging biomarker comparable to standardized uptake values (SUV) in PET/CT [15]. Preliminary data have shown an incremental value of DWI for characterizing pelvic lymph nodes and bone metastases in prostate cancer $[7,16]$. However, despite the increasing use of DWI in patients with cancer, systematic reports evaluating this technique within the concept of wholebody MRI are still limited [11, 13, 14, 17, 18].

The aim of our study, therefore, was to compare the detection rate of $11 \mathrm{C}$-choline PET/CT with that of wholebody MRI including DWI in patients with suspected recurrent prostate cancer.

\section{RESULTS}

\section{SOR}

In total, 1026 regions (57 LR, 456 LN, 456 bone, 57 other) were evaluated in 57 patients. Fifty patients had at least one positive lesion according to the SOR, 153 regions were finally regarded as positive, and 873 as negative. Twenty-four of the 57 patients included in the study showed evidence of local recurrence. Of 456 lymph node regions evaluated in the study, 59 regions in 27 patients were regarded as positive, 397 regions in 30 patients as negative. Seventy of the 456 bone regions in 22 patients were regarded as positive and 386 regions in 35 patients as negative. Seventeen of 57 patients had evidence of extra-pelvic disease. Five patients had metastases in other regions (lung in four cases, liver in two cases, and peritoneum in one case). These lesions were excluded from analysis.

\section{Detection rate on a patient basis}

$11 \mathrm{C}$-choline $\mathrm{PET} / \mathrm{CT}$ showed positive results in $94.0 \%$ (47/50 patients). MRI analysis resulted in a detection rate of $88.0 \%$ (44/50 patients). The PAC of both methods was significantly higher in the subgroup of patients with PSA values greater than $2 \mathrm{ng} / \mathrm{mL}$ compared with the subgroup with values lower than or equal to $2 \mathrm{ng} /$ $\mathrm{mL}$ (Table 2). However, there was no significant difference between the methods on a patient basis. Both, PET/CT and MRI correctly identified all patients with evidence of extra-pelvic disease (showing at least one positive extrapelvic lesion per patient). For 11C-Choline PET/CT mean imaging time was calculated as $18.4 \mathrm{~min} \pm 0.7 \mathrm{~min}$ (range 17 - $21 \mathrm{~min})$. For 11C-Choline PET/MR mean imaging time was $50.4 \mathrm{~min} \pm 7.9 \mathrm{~min}$ (range 42 - $92 \mathrm{~min}$ ).

\section{Regional lesion detection}

The sensitivity and overall PAC of 11C-choline $\mathrm{PET} / \mathrm{CT}$ and PET/MR in detecting LR, LN and bone metastases on the basis of the dichotomized data is given in Table 3. In keeping with the results of the patient based evaluation, analysis of all 3 regions generally showed higher sensitivities in all patients and in the subgroup of patients with PSA values $>2 \mathrm{ng} / \mathrm{mL}$ compared to patients with PSA values $\leq 2 \mathrm{ng} / \mathrm{mL}$.

Regional analysis of all patients also revealed a significantly higher sensitivity of $11 \mathrm{C}$-choline PET/ CT compared to MRI for the detection of LR and bone metastases. However, no significant difference was found with respect to LN metastasis. Cohen's kappa analysis showed only slight agreement between PET/CT and MRI for the detection of LR (kappa 0.188, 0.027-0.349), fair agreement for LN metastases (kappa 0.349, 0.256-0.442), and moderate agreement for bone metastasis (kappa 0.582, 0.490-0.674). Both 11C-choline PET/CT and MRI generally showed a random distribution of false positives and negatives over the LN and bone regions evaluated. However, none of the false negative bone regions on MRI $(n=15)$ was located in the cervical, thoracic or lumbar spine ( 3 in the sacrum, 8 in the pelvis, and 4 in the extremities).

In the subgroup of patients with PSA values $>2$ ng/mL, 11C-choline PET/CT again showed significantly greater efficiency than MRI in detecting LR and bone metastasis, and equal results for the detection of LN 


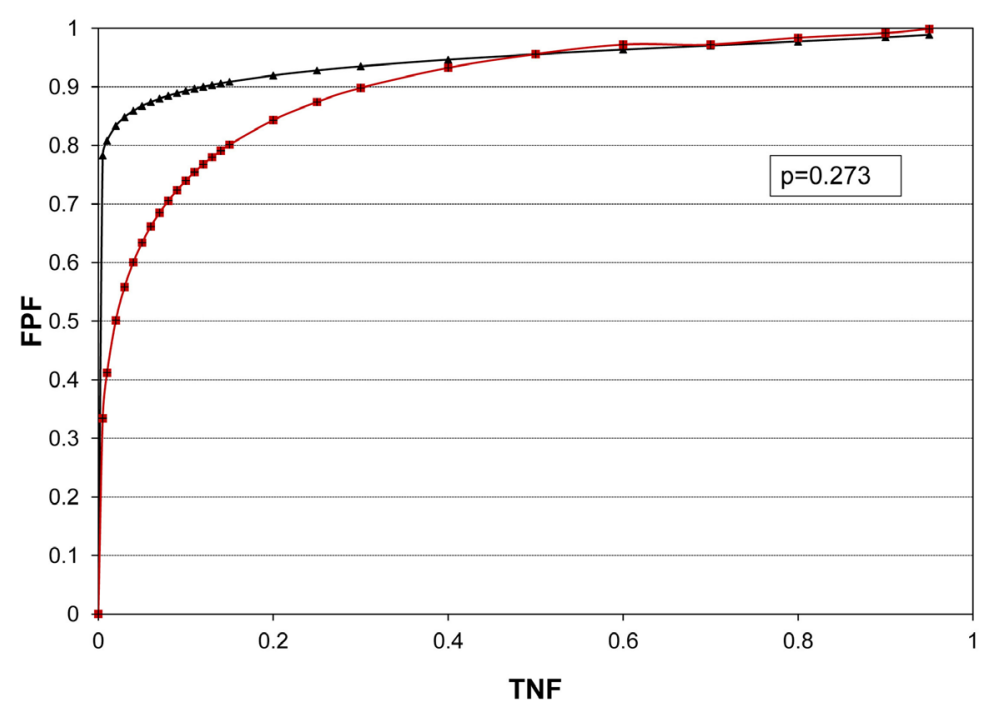

A

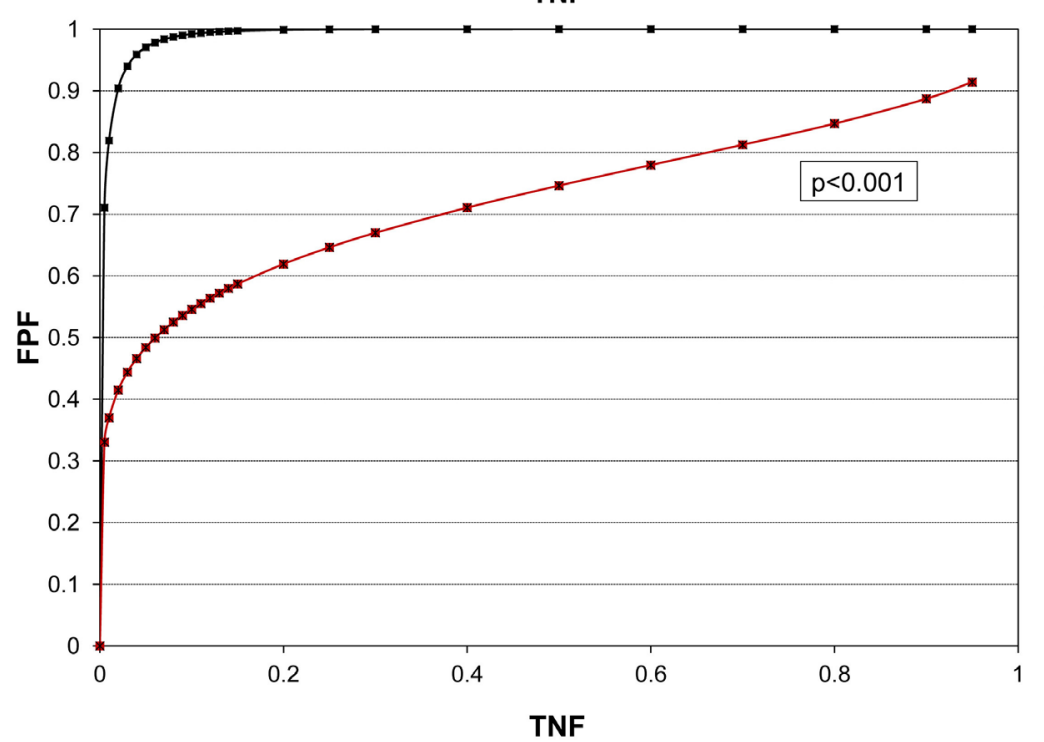

B

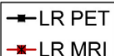

$\rightarrow$ LR MRI

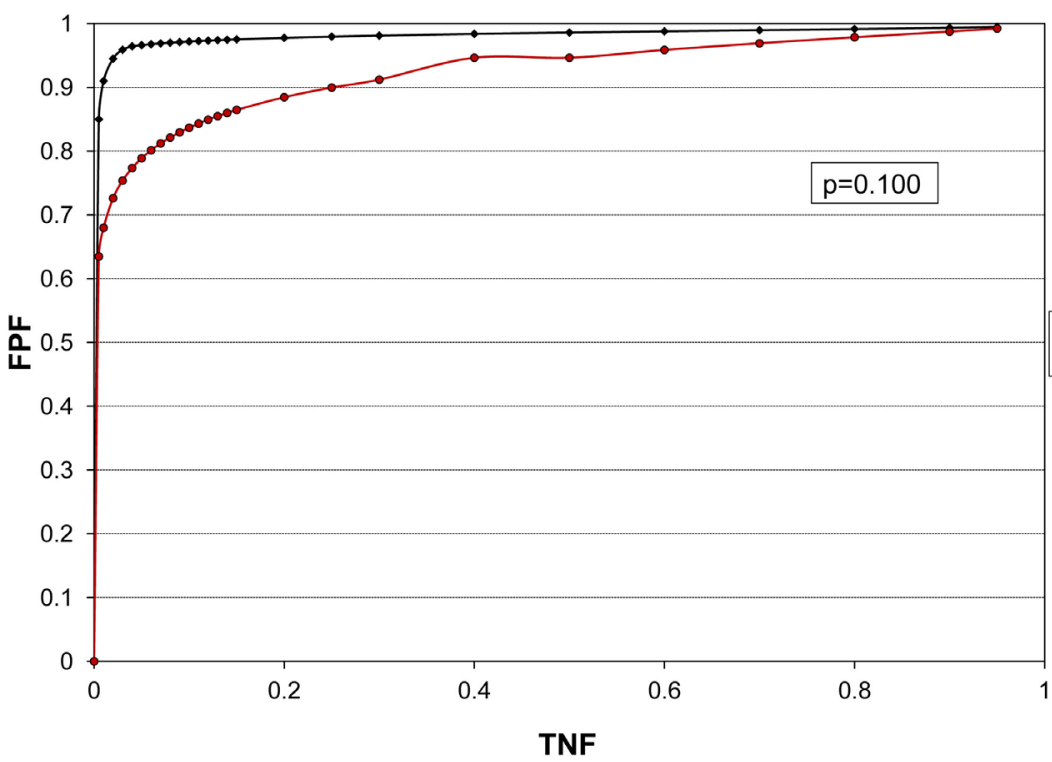

C

Figure 1: Considering all patients, ROC analysis with areas under the curve (AUC) shows no significant differences for the detection of lymph node (LN, A) metastasis. PET/CT showed significantly greater AUCs than MRI for the detection of both local recurrence (LR, B) and bone metastases (Bone, C) (see also Table 4). 
Table 1: Patient characteristics

\begin{tabular}{|l|c|}
\hline \multicolumn{1}{|c|}{ Number of patients } & $\mathbf{5 7}$ \\
\hline Primary radical prostatectomy & $100 \%$ \\
\hline Age [years] & $86(54-80)$ \\
\hline Median (range) & $8(6-9)$ \\
\hline Gleason score * & \\
\hline mean (range) & $29.9(1.0-670)$ \\
\hline PSA [ng/ml] & $42(74 \%)$ \\
\hline mean (range) & $16.0 \pm 33.4$ \\
\hline $\begin{array}{l}\text { Patients with PSA }>2.0[\mathrm{ng} / \mathrm{ml}] \\
\text { mean PSA } \pm \mathrm{SD}[\mathrm{ng} / \mathrm{ml}]\end{array}$ & $15(26 \%)$ \\
\hline $\begin{array}{l}\text { Patients with PSA } \leq 2.0[\mathrm{ng} / \mathrm{ml}] \\
\text { mean PSA } \pm \mathrm{SD}[\mathrm{ng} / \mathrm{ml}]\end{array}$ & $1.4 \pm 0.3$ \\
\hline Interval: primary treatment $-11 \mathrm{C}-$ choline PET/CT-imaging [months] & $77(6-200)$ \\
\hline median (range) & \\
\hline
\end{tabular}

* Information about the initial Gleason score could be obtained in 42 of the 57 patients.

Table 2: Overall accuracy of PET/CT and MRI for detection of local recurrence and/or metastases on a patient basis.

\begin{tabular}{|l|c|c|}
\hline \multicolumn{1}{|c|}{ PAC } & PET/CT & MRI \\
\hline All & $95.0 \% *$ & $88.0 \% *$ \\
\hline PSA $>2 \mathrm{ng} / \mathrm{ml}$ & $100.0 \% \# \dagger$ & $90.5 \%$ ฯ $\dagger$ \\
\hline PSA $\leq 2 \mathrm{ng} / \mathrm{ml}$ & $80.0 \% \# \dagger \dagger$ & $66.7 \% \uparrow \dagger$ \\
\hline
\end{tabular}

The comparison of PET/CT and MRI showed no significant difference in overall predictive accuracy (PAC) on a patient basis $\left({ }^{*} p=0.07\right)$. However, the PAC was significantly higher in the subgroup of patients with PSA level $>2 \mathrm{ng} / \mathrm{mL}$ than in patients with PSA level $\leq 2 \mathrm{ng} / \mathrm{mL}$ for both PET/CT and MRI ( $\#=0.003 ; \uparrow p=0.03$ ). Comparing PET/CT and MRI in the subgroups, $\mathrm{PET} / \mathrm{CT}$ was significantly superior to MRI in patients with PSA level $>2 \mathrm{ng} / \mathrm{mL}(\dagger \mathrm{p}=0.04)$ but not in the subgroup of patients with PSA level $\leq 2 \mathrm{ng} / \mathrm{mL}(\dagger \dagger p=0.41)$.

Table 3: Accuracy of PET/CT and MRI in detecting local recurrence, lymph node metastases, and bone metastases

\begin{tabular}{|c|c|c|c|c|c|c|}
\hline & \multicolumn{2}{|l|}{ LR } & \multicolumn{2}{|l|}{$\mathbf{L N}$} & \multicolumn{2}{|l|}{ Bone } \\
\hline & PET/CT & MRI & PET/CT & MRI & PET/CT & MRI \\
\hline \multicolumn{7}{|l|}{ All patients } \\
\hline Sensitivity & $83.3 \%(20 / 24) *$ & $54.2 \%(13 / 24) *$ & $81.4 \%(48 / 59)$ & $77.9 \%(46 / 59)$ & $92.9 \%(65 / 70)$ & $78.6 \%(55 / 70)$ \\
\hline Specificity & $93.9 \%(31 / 33)$ & $81.8 \%(27 / 33)$ & 99.7\% (396/397) & $87.5 \%(356 / 407)$ & $98.4 \%(380 / 386)$ & $87.5 \%(356 / 407)$ \\
\hline PPV & $90.9 \%(20 / 22)$ & $68.4 \%(13 / 19)$ & $97.9 \%(48 / 49)$ & $52.8 \%(46 / 87)$ & $91.5 \%(65 / 71)$ & $52.9 \%(46 / 87)$ \\
\hline NPV & $88.6 \%(31 / 35)$ & $71.1 \%(27 / 38)$ & $97.3 \%(396 / 407)$ & $96.5 \%(356 / 369)$ & $98.7 \%(380 / 385)$ & $96.5 \%(356 / 369)$ \\
\hline PAC & $89.5 \%(51 / 57)$ & $70.1 \%(40 / 57)$ & $97.4 \%(444 / 456)$ & $88.2 \%(402 / 456)$ & $97.6 \%(385 / 456)$ & $88.2 \%(402 / 456)$ \\
\hline \multicolumn{7}{|c|}{ PSA $>2 \mathrm{ng} / \mathrm{ml}$} \\
\hline Sensitivity & $90.5 \%(19 / 21) \dagger$ & $52.4 \%(11 / 21) \dagger$ & $90.5 \%(38 / 42) \S$ & $83.3 \%(35 / 42) \S$ & $95.1 \%(58 / 61) \#$ & $80.3 \%(49 / 61) \#$ \\
\hline Specificity & $90.5 \%(19 / 21)$ & $76.2 \%(16 / 21)$ & $99.7 \%(293 / 294)$ & $89.0 \%(260 / 292)$ & $98.4 \%(380 / 386)$ & $97.1 \%(267 / 275)$ \\
\hline PPV & $90.5 \%(19 / 21)$ & $68.8 \%(11 / 16)$ & $97.4 \%(38 / 39)$ & $52.2 \%(35 / 67)$ & $90.3 \%(65 / 72)$ & $85.9 \%(49 / 57)$ \\
\hline NPV & $90.5 \%(19 / 21)$ & $61.5 \%(16 / 26)$ & 98.7\% (293/297) & $97.4 \%(260 / 267)$ & $98.7 \%(380 / 385)$ & $95.7 \%(267 / 279)$ \\
\hline PAC & $90.5 \%(38 / 42)$ & $88.1 \%(37 / 42)$ & $98.5 \%(331 / 336)$ & $87.8 \%(295 / 336)$ & $97.6 \%(445 / 456)$ & $94.0 \%(316 / 336)$ \\
\hline \multicolumn{7}{|c|}{$\mathrm{PSA} \leq 2 \mathrm{ng} / \mathrm{ml}$} \\
\hline Sensitivity & $33.3 \%(1 / 3)+\dagger$ & $66.6 \%(2 / 3)+\dagger$ & $58.8 \%(10 / 17) \S \S$ & $64.7 \%(11 / 17) \S \S$ & $77.8 \%(7 / 9) \# \#$ & $66.7 \%(6 / 9) \# \#$ \\
\hline Specificity & $100 \%(12 / 12)$ & $91.7 \%(11 / 12)$ & $100 \%(103 / 103)$ & $91.4 \%(96 / 105)$ & $98.2 \%(109 / 111)$ & $95.5 \%(106 / 111)$ \\
\hline PPV & $100 \%(1 / 1)$ & $66.7 \%(2 / 3)$ & $100 \%(10 / 10)$ & $55.0 \%(11 / 20)$ & $77.8 \%(7 / 9)$ & $55.5 \%(6 / 11)$ \\
\hline NPV & $85.7 \%(12 / 14)$ & $91.7 \%(11 / 12)$ & $93.6 \%(103 / 110)$ & $94.1 \%(96 / 102)$ & 98.2\% (109/111) & $97.2 \%(106 / 109)$ \\
\hline PAC & $86.7 \%(13 / 15)$ & $86.7 \%(13 / 15)$ & $94.2 \%(113 / 120)$ & $89.2 \%(107 / 120)$ & 96.7\% (111/120) & $93.3 \%(112 / 120)$ \\
\hline
\end{tabular}

Considering all patients, PET/CT showed a significantly higher PAC than MRI for the detection of both local recurrence (LR) $(* p=0.03)$ and bone metastases (Bone) $(\Phi \uparrow p=0.02)$. Comparison of PET/CT and MRI on the basis of regions showed no significant difference in the sensitivity of the detection of lymph node (LN) metastasis $(\mathbb{\Phi} p=0.65)$. Subgroup analysis of patients with PSA $>2 \mathrm{ng} / \mathrm{mL}$ yielded similar results ( $\dagger p=0.006 ; \S p=0.33$; \# $p=0.01$ ). However, the regional differences were generally not significant for patients with PSA $\leq 2 \mathrm{ng} / \mathrm{mL}$, probably owing to the relatively low number of local recurrences and bone metastases in this subgroup $(\dagger \dagger p=0.85 ; \S \S p=0.72$; \#\# $p=0.59$ ). 
Table 4: Comparison of diagnostic performance by ROC analysis

\begin{tabular}{|l|c|c|c|}
\hline \multicolumn{1}{|c|}{ AUC } & PET/CT & MRI & $p$-value \\
\hline All patients & & & \\
\hline LR $(n=57)$ & $0.993(0.946-0.999)$ & $0.729(0.555-0.860)$ & $P=0.001$ \\
\hline LN $(n=456)$ & $0.945(0.850-0.985)$ & $0.905(0.849-0.944)$ & $P=0.273$ \\
\hline Bone $(n=456)$ & $0.984(0.900-0.998)$ & $0.925(0.893-0.971)$ & $P=0.100$ \\
\hline PSA $>\mathbf{2} \mathbf{~ n g / m l ~}$ & & & \\
\hline LR $(n=42)$ & $0.979(0.888-0.998)$ & $0.720(0.539-0.856)$ & $P=0.002$ \\
\hline LN $(n=336)$ & $0.941(0.802-0.989)$ & $0.922(0.861-0.960)$ & $P=0.653$ \\
\hline Bone $(n=336)$ & $0.982(0.888-0.999)$ & $0.923(0.816-0.974)$ & $P=0.164$ \\
\hline PSA $\leq \mathbf{2} \mathbf{n g} / \mathbf{m l}$ & & & $P=0.149$ \\
\hline LR $(n=15)$ & $0.908(0.613-0.991)$ & $0.632(0.189-0.941)$ & $P=0.264$ \\
\hline LN $(n=120)$ & $0.903(0.697-0.981)$ & $0.775(0.512-0.931)$ & $P=0.309$ \\
\hline Bone $(n=120)$ & $0.977(0.899-0.997)$ & $0.928(0.736-0.989)$ & \\
\hline
\end{tabular}

Areas under the curve (AUC) with 95\% confidence intervals given in brackets. Considering all patients, the ROC analyses showed no significant differences in AUCs for the detection of lymph node metastasis (LN). Compared with MRI, PET/CT showed significantly greater AUCs in the detection of both local recurrence (LR) and bone metastasis (Bone). Subgroup analysis of patients with PSA $>2 \mathrm{ng} / \mathrm{mL}$ showed a significant difference for the detection of local recurrence. Regional differences were generally not significant for patients with PSA $\leq 2 \mathrm{ng} / \mathrm{mL}$.

metastasis. Differences between the two methods were also apparent in the subgroup of patients with PSA values $\leq 2 \mathrm{ng} / \mathrm{mL}$ but failed to reach the level of statistical significance.

Table 4 shows the data on the diagnostic performance using ROC analysis. The ROC graphs separated for LR, LN, and bone metastases are shown in Figure 1a-1c.

\section{DISCUSSION}

Approximately one-third of patients with prostate cancer will have a recurrence of disease after definitive treatment with surgery or external radiation [19]. In most patients, recurrence is suspected because of an increase in PSA levels, which may precede clinically detectable disease by months or even years. Traditionally, screening for distant metastasis requires a combination of radionuclide bone scanning, CT, and MRI. Each of these techniques has its limitations and an accurate non-invasive method for guiding pathological confirmation on a wholebody basis is greatly to be desired [20].

We set out to determine the diagnostic performance of $11 \mathrm{C}$-choline PET/CT in detecting recurrent disease in patients with prostate cancer, and to compare it with that of whole-body MRI including DWI. The overall detection rate for 11C-Choline PET/CT was higher compared to a study of Castellucci and colleagues (about 39\%) probably owing to the high PSA level in our study cohort [15]. However, the detection rate of MRI with DWI was lower than we might have expected from studies using DWI or contrast enhanced MRI protocols [21, 22]. Both, 11C-choline PET/CT and MRI showed variable diagnostic accuracy for detecting LR, LN metastases, and bone metastases on a regional basis. The efficacy of 11C-choline $\mathrm{PET} / \mathrm{CT}$ in detecting LR and bone metastases was clearly better than that of MRI including DWI. With respect to the detection of LN metastases, we did not find a significant difference in the accuracy of the two methods. The PSA level significantly influenced the overall accuracy of both PET/CT and MRI. This is in agreement with the findings of other studies that have investigated the dependence of $11 \mathrm{C}$-choline PET/CT detection on PSA values in the setting of biochemical recurrence [15, 23].

Lesions to the lungs and visceral organs were relatively infrequent in our study. However, we excluded those from analysis because of inherent limitations of both MRI (concerning the lung lesions) and PET (concerning liver lesions). Compared to PET/CT, the MRI acquisition time was significantly longer which represents a potential limitation regarding patient throughput. Ten patients had to be excluded from the study because of general MRI contraindications also representing a limitation of this imaging method.

\section{Local recurrence}

However, the diagnosis of LR after radical prostatectomy is often challenging. Souvatzoglou et al. found that only seven (19\%) of 37 patients with low PSA 


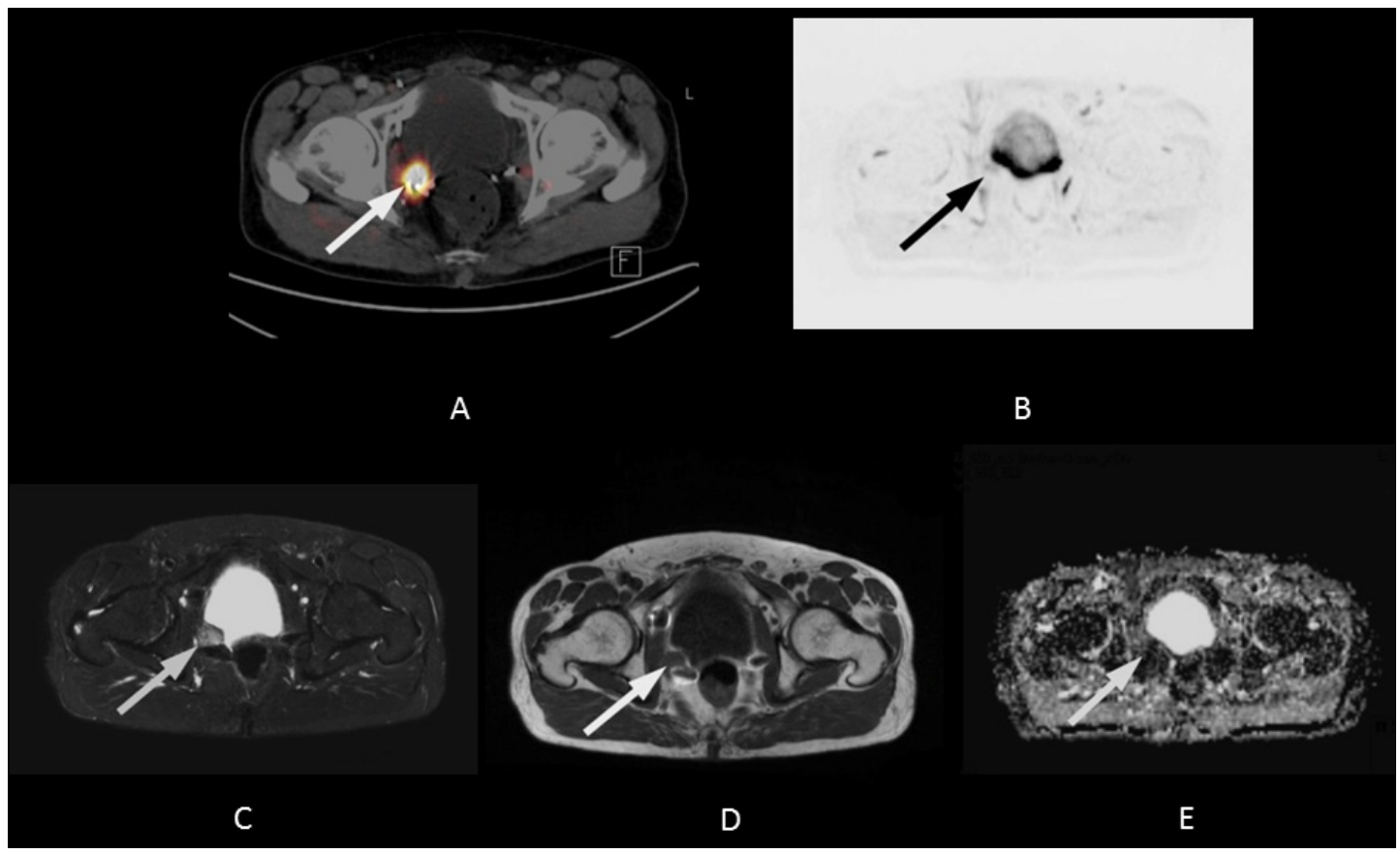

Figure 2: 68-year-old patient with local recurrence 13 years after radical prostatectomy (initial Gleason Score: 8). The PSA level at the time of imaging was $2.1 \mathrm{ng} / \mathrm{mL}$. A fall in PSA level after pelvic irradiation confirmed the lesion was malignant $(<1.0 \mathrm{ng} /$ $\mathrm{mL}$ after radiotherapy). A. The axial PET/CT fusion image shows focal 11C-choline uptake in the area of the right neurovascular bundle (white arrow, SUV max 4.2). B. The lesion was not visible on the $500 \mathrm{~ms} \mathrm{~b}$-image (B) or the ADC map (not shown) of the DWI. Both the STIR image C. and the T1w image D. show susceptibility artefacts due to surgical clips in the area of focal 11C-choline uptake. Part of the lesion, however, remains visible in spite of some signal loss (white arrows).

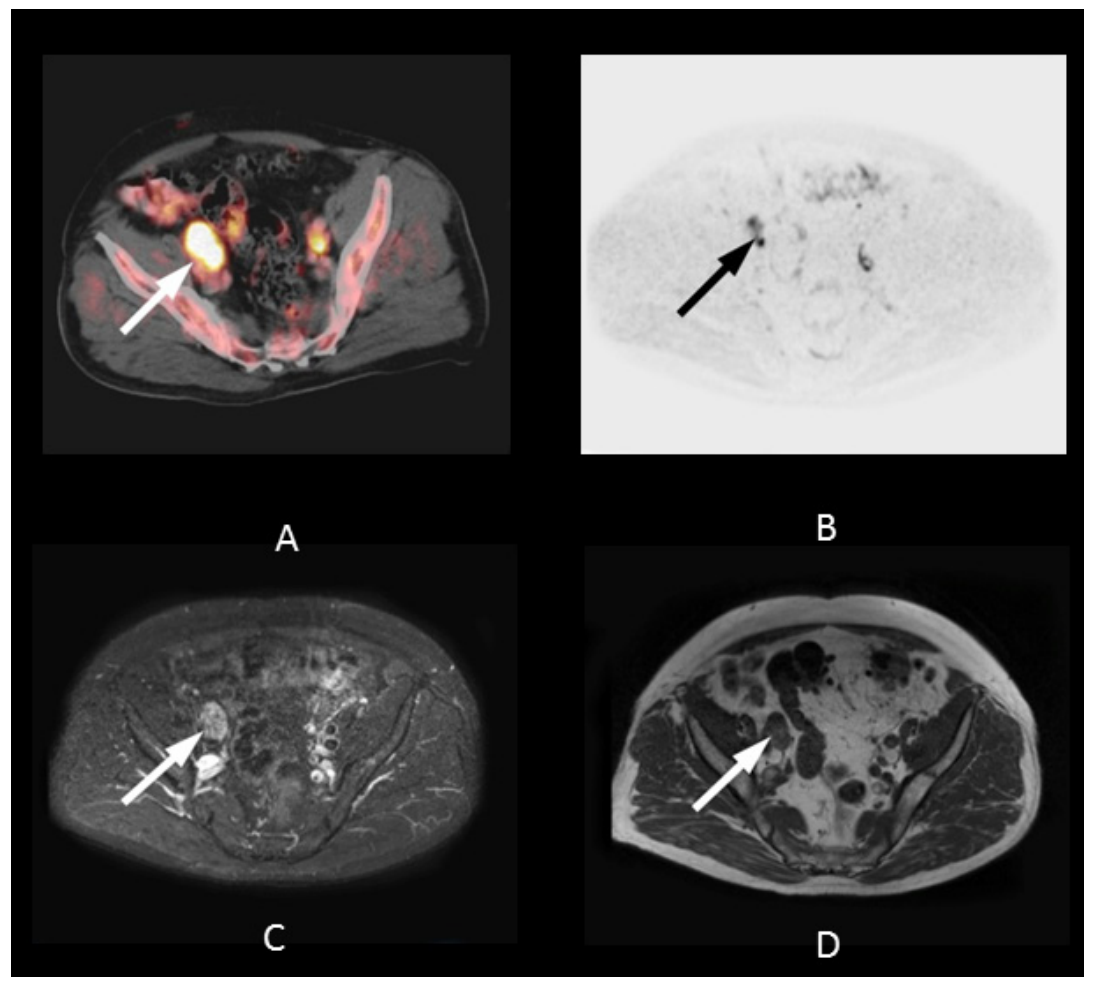

Figure 3: 74-year-old patient with lymph node metastases six years after radical prostatectomy (initial Gleason Score: 7). The PSA level at the time of imaging was $21.0 \mathrm{ng} / \mathrm{mL}$. A regression in lesion size after pelvic irradiation confirmed the malignant nature of the lesions. A. Axial PET/CT fusion image showing focal 11C-choline uptake in the area of the right external iliac vessels (white arrow, SUV max 3.6). The lesion shows focal signal elevation on both the $500 \mathrm{~ms}$ b-image using DWI B. (black arrow) and the STIR image $\mathbf{C}$. (white arrow). D. Axial fusion T1w image showing enlarged lymph nodes $(20 \mathrm{~mm})$ close to the right external iliac vein. 
values (PSA range, 0.3-1.8 ng/mL) who were referred for salvage radiotherapy showed an increased uptake in the prostatectomy bed using 11C-choline PET/CT [24]. Panebianco et al. compared multiparametric MRI and 18F-choline PET/CT for detecting LR after radical prostatectomy in 84 patients and showed MRI to be superior, notably in patients with smaller lesions $(<7 \mathrm{~mm})$ and low PSA values [21]. However, their MRI protocol included dedicated sequences for the pelvis, e.g. dynamic contrast enhanced (DCE) imaging, which we did not use in our study so as to stay within a reasonable time frame for whole-body imaging. In addition, the limited number of patients with PSA values $<2 \mathrm{ng} / \mathrm{mL}$ in our study might have contributed to results in favour of 11C-choline PET/ CT. A recent study on whole-body MRI in combination with dedicated MR for the Prostate showed disease recurrence in only $21 \%(16 / 76)$ of $\mathrm{PC}$ patients having with median PSA of $0.36 \mathrm{ng} / \mathrm{mL}$ (range 0.05-56.12) [25].

A wide variety of entities can mimic recurrent prostate cancer on MRI. Retained seminal vesicles, fibrotic scaring, a prominent peri-prostatic venous plexus, and granulation tissue can all lead to false positive results [26]. In addition, susceptibility artefacts due to surgical paramagnetic material may also diminish the accuracy of MRI in the detection of LR (Figure 2).

\section{Lymph nodes}

The evaluation of LN metastases is crucial in restaging patients with PSA failure after radical prostatectomy. Recent studies have evaluated the diagnostic performance of MRI with DWI and 11C-choline PET/CT in preoperative lymph node staging, yielding varying results. In a patient-based analysis of 132 patients, Beheshti et al. obtained a sensitivity of $66 \%$ and specificity of $96 \%$ in lymph nodes larger than $5 \mathrm{~mm}$ when using 11C-choline PET/CT [27]. In a cohort of 29 patients, Eiber et al. calculated a sensitivity of $86 \%$ and specificity of $85.3 \%$ for DWI of pelvic lymph nodes in prostate cancer [28]. In contrast, Budiharto et al. reported disappointing results in a group of 36 high-risk prostate

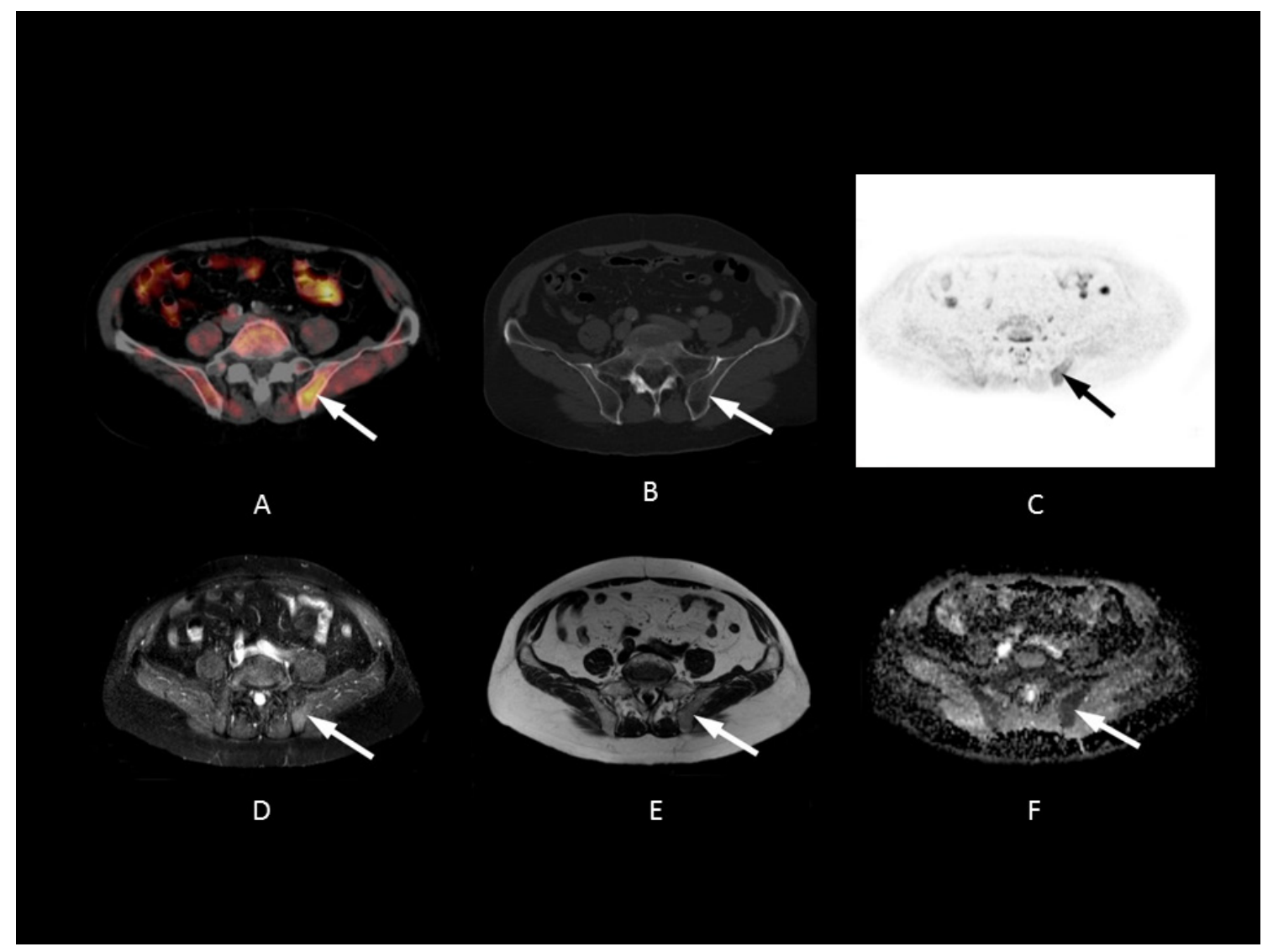

Figure 4: 54-year-old patient with bone metastasis in the left pelvis nine years after radical prostatectomy (initial Gleason Score: 8). The PSA level at the time of imaging was $2.3 \mathrm{ng} / \mathrm{mL}$. A fall in PSA level after pelvic irradiation confirmed a malignant lesion (1.0 ng/mL after radiation therapy). A. Axial PET/CT fusion image showing a focal 11C-choline uptake in the area of the posterior iliac bone (white arrow, SUV max 3.97). B. The lesion shows no substantial sclerosis (HU 708) and is hardly visible on CT. C. Axial 500 $\mathrm{ms}$ b-image and $\mathbf{D}$. ADC map showing only a slight signal abnormality of the lesion in the left iliac bone (relative ADC lesion/normal bone: 1.02) (white and black arrows). E. The STIR image shows slight focal signal elevation (relative STIR SI lesion/normal bone: 0.90 ) and F. slight signal distortion can be seen on the T1w image (white arrow, relative SI lesion/normal bone: 1.05). 
cancer patients [29]. The sensitivity in a per-patient analysis was only $43 \%$ with a specificity of $98 \%$. We found equal diagnostic accuracy for 11C-choline PET/ CT and MRI. The relatively high overall detection rate for both methods in our study might be due to summarizing multiple nodes to regions, in contrast to a true lesion-bylesion analysis based on histopathology, as performed in other investigations (Figure 3) [30].

\section{Bone}

MRI with DWI is increasingly being used to assess bone marrow and metastatic disease, because it is sensitive to bone marrow cell density, the relative proportions of fat and marrow cells, water content, and bone marrow perfusion [31]. In a recently published meta-analysis, the ability of DWI to improve sensitivity for bony metastasis detection was shown to be at the expense of a slight reduction in specificity [32].

As a general rule in DWI, however, lytic bony metastases are seen more clearly than pure sclerotic metastases, because of the lower water and cellular content of sclerotic and treated lesions [33]. As a result, DWI may not show purely sclerotic bone metastases very well. In addition, cortical bone, with its very short T2 and long $\mathrm{T} 1$ relaxation time, is very poorly interrogated. This might have contributed to our results showing greater accuracy for $11 \mathrm{C}$-choline PET/CT than MRI in recurrent prostate cancer with predominantly sclerotic bone metastases (Figure 4). However, some studies also showed lower $11 \mathrm{C}$-Chloline uptake in sclerotic metastases compared to osteolytic lesions [34]. All false negative bone lesions on MRI were located in sites outside of the cervical, thoracic and lumbar spine, with a lower marrow content in relation to cortical structures.

\section{Limitations}

This study has certain limitations. The high mean PSA values indicate a clear selection bias for which a high positive rate was to be expected. Most patients were at high risk of recurrent disease, with a high prevalence of metastases at the time of recurrence. Most of the patients had at least one positive lesion. Thus, the "true" specificity of the methods cannot be determined. A histological examination in all patients would have been optimal but was not possible for practical and ethical reasons.

Instead of a lesion-based analysis of LN metastases, we made region- and patient-based comparisons between imaging and SOR. We chose this approach in consideration of the fact that it is technically extremely challenging to map multiple LNs exactly within a field and correlate each LN with imaging and SOR. However, even this field-wise approach is prone to error when comparing imaging results with follow-up studies.

The use of dedicated sequences for the pelvis, such as DCE imaging, could have improved the accuracy of LR detection. However, we did not use such techniques, in order to stay within a reasonable time frame for wholebody imaging. Significantly more time was needed for MR image acquisition compared to that of PET/CT.

\section{CONCLUSIONS}

11C-choline PET/CT was superior to whole-body MRI with DWI in the detection of local recurrence and bone metastasis on a regional basis. The two methods showed equal diagnostic accuracy for detecting lymph node metastases. In summary, whole-body MRI with DWI cannot be recommended as an alternative to $11 \mathrm{C}$-choline $\mathrm{PET} / \mathrm{CT}$. In initial studies, 68Ga-PSMA PET/CT was shown to further enhance the accuracy of PET/CT for recurrent prostate cancer.

\section{MATERIALS AND METHODS}

\section{Patients}

Fifty-seven patients underwent 11C-Choline PET/ $\mathrm{CT}$ for restaging of $\mathrm{PC}$, which was sort of "routine" in the setting of suspected recurrence of $\mathrm{PC}$ during the time of data acquisition. MRI was added as part of our study protocol. Recruitment was performed in an outpatient clinic based on willingness to participate and on the absence of MRI contraindications. During the enrolment period, 10 patients were not eligible for the study because of MRI contraindications (replacements, cardiac devices). Only patients who had undergone radical prostatectomy were eligible for the study. Patients after chemotherapy or after second line hormonal treatment were excluded. No further patient selection was performed to avoid bias and to ensure a broad spectrum of PSA-values. All patients had MRI and 11C-choline PET/CT scans within 1-3 days (mean 1.1 day). For every patient the imaging time needed for 11C-Choline PET/CT and MRI was analyzed (time from scout scan or localizer to the end of acquisition). The mean PSA was $29.9 \mathrm{ng} / \mathrm{mL}$ (range 1.0-670 ng/mL). The institutional review board approved the study and all patients gave their informed consent. Table 1 shows the patient characteristics.

\section{MRI}

MRI was performed using a 1.5T MR scanner (Magnetom Avanto, Siemens Medical Solutions, Erlangen, Germany). Two anterior 6-element body matrix coils were used in conjunction with two posterior spine clusters (three channels each) to optimize the signal-to-noise ratio (SNR). In addition, a 12-element head matrix coil, a 4-element neck matrix coil, and a 6-element peripheral 
matrix coil were used. The maximum imaging range in the $\mathrm{z}$-axis was $160 \mathrm{~cm}$ with automated table motion. A total of four axial stacks encompassing the base of the skull to the proximal thighs were acquired. According to the convention derived from various reports in the literature $[11,14,35]$, the examination was referred to as a whole-body examination, despite the fact that part of the lower extremities was not included in the imaging field. Axial echo-planar DW sequences including background suppression with spectral selection attenuated inversion recovery (SPAIR) and b-values of 50 and $500 \mathrm{~s} / \mathrm{mm}^{2}$ were acquired. The selection of a high b-value of $500 \mathrm{~s} /$ $\mathrm{mm}^{2}$ was based on a trade-off between signal intensity and adequate diffusion strength and was consistent with recommendations given in a consensus paper on the use of DWI in cancer patients [36].

The other technical parameters were as follows: 5 mm slice thickness without intersection gap; number of excitations 3; and generalized autocalibrating partially parallel acquisition (GRAPPA). DWI was achieved by applying pairs of motion-probing gradients before and after the $180^{\circ}$ radiofrequency pulse of the spin-echo T2weighted sequence in three orthogonal directions. ADC maps were calculated from all diffusion weightings and directions on a voxel-by-voxel basis. Conventional T1weighted (T1w) turbo spin echo (TSE) and short-tau inversion recovery (STIR) images were acquired from the base of the skull to the proximal thigh in axial orientation and for the whole spine in the sagittal plane.

\section{PET/CT}

\section{Synthesis of 11C-choline}

With minor modifications, 11C-choline was produced according to the method described by Hara et al. [37]. In brief, $11 \mathrm{C}-\mathrm{CO}_{2}$ was converted to $11 \mathrm{C}-\mathrm{CH}_{3} \mathrm{I}$ by the catalytic gas-phase iodination reaction via $11 \mathrm{C}-\mathrm{CH}_{4}(\mathrm{GE}$ MeI MicroLab). 11C-CH $\mathrm{I}$, swept with a helium flow at 50 $\mathrm{ml} / \mathrm{min}$, was passed through a Light-CM cartridge loaded with N,N-dimethylethanolamine $(25 \mu \mathrm{l})$. The column was washed with $10 \mathrm{ml}$ ethanol followed by $10 \mathrm{ml}$ water before eluting the product with isotonic saline $(2-5 \mathrm{ml}$ of $0.9 \%$ $\mathrm{NaCl}$ ) through a Millipore filter (Millex GS, $0.22 \mu \mathrm{m}$ ) into a sterile vial. Quality control was performed using HPLC (LiChrosorb RP18, 250×4.6 mm; $1 \mathrm{mM}$ sodium naphthalene sulfonic acid, $50 \mathrm{mM} \mathrm{M} \mathrm{H} \mathrm{PO}_{4}, 1.5 \mathrm{ml} / \mathrm{min}$; $\mathrm{k}=3.7$ ).

\section{C-choline PET/CT}

Patients fasted for at least 6 hours before $11 \mathrm{C}$-choline PET. Five minutes after the injection of 600 $900 \mathrm{MBq} 11 \mathrm{C}$-choline, patients underwent PET/CT (neck to pelvis) in a Siemens Sensation 16 Biograph PET/CT scanner. A diagnostic CT scan was performed prior to PET in the portal venous phase (80 s) after the intravenous injection of contrast agent (Imeron 300) (240 mAs, 120kV,
$0.5 \mathrm{~s}$ per rotation, $5 \mathrm{~mm}$ reconstructed slice thickness). All patients received diluted oral contrast (Telebrix 300, 30 $\mathrm{ml} / \mathrm{L})$ and rectal filling (100-150 ml). PET scans were acquired in 3D-mode with an acquisition time of 3 minutes per bed position. Iterative reconstruction of the emission data was performed using an ordered-subsets expectation maximization (OSEM) algorithm.

\section{Image analysis}

MRI and 11C-choline PET/CT scans were analyzed independently by two readers (JCS and HW). The readers were blinded to patient data except for the history of prostate cancer with suspected recurrence on basis of PSA elevation. To avoid any learning bias, all datasets were analyzed in random order with an interval of eight weeks between PET and MRI data.

The presence or absence of local recurrence (LR), lymph node (LN), bone or other metastases was evaluated for each patient and imaging modality. As it was not feasible to compare imaging modalities with the standard of reference (SOR) for single LN or bone metastases, we evaluated specific regions as a whole (for bone metastases: cervical, thoracic, and lumbar spine, ribs, right and left sides of the pelvis, upper and lower extremities; for LN metastases: external, internal and common iliac groups on each side, retroperitoneal nodes, supradiaphragmatic nodes). Any other visceral metastases (e.g. in the lungs or liver) were evaluated as one additional region per patient. For each of the anatomical locations, the probability of local recurrence and/or metastases was evaluated using a qualitative 5-point scoring system: definitely present (score 5); probably present (score 4); equivocal (score 3); probably absent (score 2); and definitely absent (score 1). Discordant readings from the two observers were resolved by consensus for each modality.

\section{PET analysis}

Focal 11C-choline activity in the prostatectomy bed greater than adjacent background uptake and not due to radiotracer excreted in the urine was rated 4 or 5 , regardless of any corresponding structural abnormality. LNs were rated 4 or 5 if distinct focal activity greater than adjacent background uptake on PET images corresponded to a visible LN on CT, regardless of size; LNs distal to the mid external iliac chains were excluded because increased radiotracer activity in these regions is common [38]. Focal skeletal sites of uptake above background marrow activity were rated 4 or 5 , unless explanatory post-traumatic or degenerative changes were evident. The presence of extrapelvic metastatic lesions was recorded in the same way. 


\section{MRI analysis}

Mass-like low T2 signal intensity with diffusion restriction in the prostatectomy bed or in the area of the former neurovascular bundle was taken to be significant for LR and was subsequently rated as 4 or 5 . LN involvement was rated on the basis of at least one lymph node per region showing increased signal intensity on inverted b-images: short-axis diameter $>10 \mathrm{~mm}$ (score 5), 8-9.9 mm (score 4), 5-7.9 mm (score 3), 1-4.9 mm (score 2 ), and not seen (score 1). Metastasis to the bone marrow was assumed in focal lesions with an increased signal in the DWI inverted b-image together with signal loss in the corresponding $\mathrm{T} 1 \mathrm{w}$ images (lower than muscle).

\section{Standard of reference (SOR)}

The standard of reference was either biopsy and histopathology or clinical follow-up. Histopathology was performed in 14 of the 57 patients (two LR, six LN and six bone metastases). Follow-up was used in 43 of the 57 patients supervised by a tumor board consisting of a nuclear medicine physician, a radiologist, and an urologist. A consensus was obtained using information from prior and subsequent imaging studies and/or clinical data (e.g. start of anti-hormonal therapy or radiotherapy). Followup consisted of all the clinical information available after study imaging, including clinical examinations, laboratory tests, radiological procedures, and histopathology from surgical procedures performed at a later date. Five patients died from causes unrelated to prostate cancer during the follow-up period. Minimum follow up time per patient was 24 month (mean 30 months, 24-38 months). Followup imaging was done using contrast enhanced CT from thorax-pelvis covering all regions except for the upper and lower extremities. Bone metastases to the extremities were judge in context with other lesions in areas that were covered by CT; there were no solitary or extensive lesions in the extremities that would have required dedicated follow-up imaging. Otherwise judgment of follow-up imaging was based on regions. A significant increase in PSA during follow-up, PSA doubling time $<10$ months, confirmation or development of a detectable lesion on follow-up imaging, an increase in lesion size, and a decrease in PSA in response to treatment (irradiation, antiandrogen or chemotherapy) were all considered indicative of malignancy $[4,5]$.

\section{Statistics}

In order to determine the diagnostic value of each method, receiver operating characteristic curves (ROC) were analyzed on a per region basis. The number of regions detected by MRI and 11C-choline PET/CT were compared with the SOR. Cohen's kappa was used to determine the agreement between the methods on the basis of score points. Agreement was considered to be slight for $\kappa<0.21$, fair for $\kappa=0.21-0.40$, moderate for $\kappa=0.41-0.60$, substantial for $\kappa=0.61-0.80$, and almost perfect for $\kappa=0.81-1.00$ [39]. Sensitivity, specificity, positive predictive values (PPV), negative predictive values (NPV), and overall predictive accuracy (PAC) were calculated after dichotomization of the score data for each region (score of 4-5: positive for PC lesion; score of 1-3: negative for $\mathrm{PC}$ lesion). Comparison of proportions for detecting LR, LN or bone metastases using MRI or $11 \mathrm{C}$-choline PET/CT was performed using the chi-square test. The difference in imaging time for MRI and PET/CT was calculated using the student t-test. A p-value less than 0.05 was considered statistically significant.

\section{Author's contribution}

Designed the study, supervised the project, analyzed the data, and wrote the paper: HW, ME, and JS. Performed the study, analyzed data, evaluated and discussed results, and edited the manuscript: $\mathrm{AB}, \mathrm{SS}, \mathrm{KH}, \mathrm{MH}, \mathrm{TM}$, and ER.

\section{CONFLICTS OF INTEREST}

The authors declare no conflicts of interest. There was no external financial support.

\section{REFRENCES}

1. Ferlay J, Steliarova-Foucher E, Lortet-Tieulent J, Rosso S, Coebergh JW, Comber H, Forman D, Bray F. Cancer incidence and mortality patterns in Europe: estimates for 40 countries in 2012. Eur J Cancer. 2013; 49:1374-403.

2. Freedland SJ, Presti JC Jr, Amling CL, Kane CJ, Aronson WJ, Dorey F, Terris MK, SEARCH Database Study Group. Time trends in biochemical recurrence after radical prostatectomy: results of the SEARCH database. Urology. 2003; 61:736-41.

3. Chism DB, Hanlon AL, Horwitz EM, Feigenberg SJ, Pollack A. A comparison of the single and double factor high-risk models for risk assignment of prostate cancer treated with 3D conformal radiotherapy. Int J Radiat Oncol Biol Phys. 2004; 59:380-85.

4. Tuncel M, Souvatzoglou M, Herrmann K, Stollfuss J, Schuster T, Weirich G, Wester HJ, Schwaiger M, Krause BJ. [(11)C]Choline positron emission tomography/ computed tomography for staging and restaging of patients with advanced prostate cancer. Nucl Med Biol. 2008; 35:689-95.

5. Krause BJ, Souvatzoglou M, Tuncel M, Herrmann K, Buck AK, Praus C, Schuster T, Geinitz H, Treiber U, Schwaiger $\mathrm{M}$. The detection rate of $[11 \mathrm{C}]$ choline-PET/CT depends 
on the serum PSA-value in patients with biochemical recurrence of prostate cancer. Eur J Nucl Med Mol Imaging. 2008; 35:18-23.

6. Weber WA, Grosu AL, Czernin J. Technology Insight: advances in molecular imaging and an appraisal of PET/CT scanning. Nat Clin Pract Oncol. 2008; 5:160-70.

7. Beer AJ, Eiber M, Souvatzoglou M, Schwaiger M, Krause BJ. Radionuclide and hybrid imaging of recurrent prostate cancer. Lancet Oncol. 2011; 12:181-91.

8. Afshar-Oromieh A, Haberkorn U, Eder M, Eisenhut M, Zechmann CM. [68Ga]Gallium-labelled PSMA ligand as superior PET tracer for the diagnosis of prostate cancer: comparison with 18F-FECH. Eur J Nucl Med Mol Imaging. 2012; 39:1085-86.

9. Lauenstein TC, Goehde SC, Herborn CU, Goyen M, Oberhoff C, Debatin JF, Ruehm SG, Barkhausen J. Wholebody MR imaging: evaluation of patients for metastases. Radiology. 2004; 233:139-48.

10. Schmidt GP, Baur-Melnyk A, Haug A, Heinemann V, Bauerfeind I, Reiser MF, Schoenberg SO. Comprehensive imaging of tumor recurrence in breast cancer patients using whole-body MRI at 1.5 and 3 T compared to FDG-PET-CT. Eur J Radiol. 2008; 65:47-58.

11. Takahara T, Imai Y, Yamashita T, Yasuda S, Nasu S, Van Cauteren M. Diffusion weighted whole body imaging with background body signal suppression (DWIBS): technical improvement using free breathing, STIR and high resolution 3D display. Radiat Med. 2004; 22:275-82.

12. Nakanishi K, Kobayashi M, Nakaguchi K, Kyakuno M, Hashimoto N, Onishi H, Maeda N, Nakata S, Kuwabara M, Murakami T, Nakamura H. Whole-body MRI for detecting metastatic bone tumor: diagnostic value of diffusionweighted images. Magn Reson Med Sci. 2007; 6:147-55.

13. Ohno Y, Koyama H, Onishi Y, Takenaka D, Nogami M, Yoshikawa T, Matsumoto S, Kotani Y, Sugimura K. Nonsmall cell lung cancer: whole-body MR examination for M-stage assessment-utility for whole-body diffusionweighted imaging compared with integrated FDG PET/CT. Radiology. 2008; 248:643-54.

14. Takenaka D, Ohno Y, Matsumoto K, Aoyama N, Onishi Y, Koyama H, Nogami M, Yoshikawa T, Matsumoto S, Sugimura K. Detection of bone metastases in non-small cell lung cancer patients: comparison of whole-body diffusionweighted imaging (DWI), whole-body MR imaging without and with DWI, whole-body FDG-PET/CT, and bone scintigraphy. J Magn Reson Imaging. 2009; 30:298-308.

15. Castellucci P, Fuccio C, Nanni C, Santi I, Rizzello A, Lodi F, Franceschelli A, Martorana G, Manferrari F, Fanti S. Influence of trigger PSA and PSA kinetics on 11C-Choline $\mathrm{PET} / \mathrm{CT}$ detection rate in patients with biochemical relapse after radical prostatectomy. J Nucl Med. 2009; 50:1394 400.

16. Luboldt W, Küfer R, Blumstein N, Toussaint TL, Kluge A, Seemann MD, Luboldt HJ. Prostate carcinoma: diffusion- weighted imaging as potential alternative to conventional $\mathrm{MR}$ and 11C-choline PET/CT for detection of bone metastases. Radiology. 2008; 249:1017-25.

17. Kwee TC, Takahara T, Ochiai R, Katahira K, Van Cauteren M, Imai Y, Nievelstein RA, Luijten PR. Whole-body diffusion-weighted magnetic resonance imaging. Eur J Radiol. 2009; 70:409-17.

18. Taouli B, Sandberg A, Stemmer A, Parikh T, Wong $\mathrm{S}, \mathrm{Xu} \mathrm{J}$, Lee VS. Diffusion-weighted imaging of the liver: comparison of navigator triggered and breathhold acquisitions. J Magn Reson Imaging. 2009; 30:561-68.

19. Mohler JL. The $2010 \mathrm{NCCN}$ clinical practice guidelines in oncology on prostate cancer. J Natl Compr Canc Netw. 2010; 8:145.

20. Kelloff GJ, Choyke P, Coffey DS, Prostate Cancer Imaging Working Group. Challenges in clinical prostate cancer: role of imaging. AJR Am J Roentgenol. 2009; 192:1455-70.

21. Panebianco V, Sciarra A, Lisi D, Galati F, Buonocore V, Catalano C, Gentile V, Laghi A, Passariello R. Prostate cancer: 1 HMRS-DCEMR at $3 \mathrm{~T}$ versus $[(18) \mathrm{F}]$ choline PET/ $\mathrm{CT}$ in the detection of local prostate cancer recurrence in men with biochemical progression after radical retropubic prostatectomy (RRP). Eur J Radiol. 2012; 81:700-08.

22. Chen W, Jian W, Li HT, Li C, Zhang YK, Xie B, Zhou DQ, Dai YM, Lin Y, Lu M, Huang XQ, Xu CX, Chen L. Whole-body diffusion-weighted imaging vs. FDG-PET for the detection of non-small-cell lung cancer. How do they measure up? Magn Reson Imaging. 2010; 28:613-20.

23. Giovacchini G, Picchio M, Coradeschi E, Bettinardi V, Gianolli L, Scattoni V, Cozzarini C, Di Muzio N, Rigatti P, Fazio F, Messa C. Predictive factors of [(11)C $]$ choline $\mathrm{PET} / \mathrm{CT}$ in patients with biochemical failure after radical prostatectomy. Eur J Nucl Med Mol Imaging. 2010; 37:301-09.

24. Souvatzoglou M, Krause BJ, Purschel A, Thamm R, Schuster T, Buck AK, Zimmermann F, Molls M, Schwaiger $\mathrm{M}$, Geinitz H. Influence of (11)C-choline PET/CT on the treatment planning for salvage radiation therapy in patients with biochemical recurrence of prostate cancer. Radiother Oncol. 2011; 99:193-200.

25. Robertson NL, Sala E, Benz M, Landa J, Scardino P, Scher HI, Hricak H, Vargas HA. Combined Whole Body and Multiparametric Prostate Magnetic Resonance Imaging as a 1-Step Approach to the Simultaneous Assessment of Local Recurrence and Metastatic Disease after Radical Prostatectomy. J Urol. 2017 Feb 16. doi: 10.1016/j. juro.2017.02.071. [Epub ahead of print]

26. Sella T, Schwartz LH, Swindle PW, Onyebuchi CN, Scardino PT, Scher HI, Hricak H. Suspected local recurrence after radical prostatectomy: endorectal coil MR imaging. Radiology. 2004; 231:379-85.

27. Beheshti M, Imamovic L, Broinger G, Vali R, Waldenberger P, Stoiber F, Nader M, Gruy B, Janetschek G, Langsteger W. $18 \mathrm{~F}$ choline PET/CT in the preoperative staging of 
prostate cancer in patients with intermediate or high risk of extracapsular disease: a prospective study of 130 patients. Radiology. 2010; 254:925-33.

28. Eiber M, Beer AJ, Holzapfel K, Tauber R, Ganter C, Weirich G, Krause BJ, Rummeny EJ, Gaa J. Preliminary results for characterization of pelvic lymph nodes in patients with prostate cancer by diffusion-weighted MR-imaging. Invest Radiol. 2010; 45:15-23.

29. Budiharto $\mathrm{T}$, Joniau S, Lerut E, Van den Bergh L, Mottaghy F, Deroose CM, Oyen R, Ameye F, Bogaerts K, Haustermans K, Van Poppel H. Prospective evaluation of 11C-choline positron emission tomography/computed tomography and diffusion-weighted magnetic resonance imaging for the nodal staging of prostate cancer with a high risk of lymph node metastases. Eur Urol. 2011; 60:125-30.

30. Scattoni V, Picchio M, Suardi N, Messa C, Freschi M, Roscigno M, Da Pozzo L, Bocciardi A, Rigatti P, Fazio F. Detection of lymph-node metastases with integrated [11C] choline PET/CT in patients with PSA failure after radical retropubic prostatectomy: results confirmed by open pelvicretroperitoneal lymphadenectomy. Eur Urol. 2007; 52:42329.

31. Biffar A, Dietrich O, Sourbron S, Duerr HR, Reiser MF, Baur-Melnyk A. Diffusion and perfusion imaging of bone marrow. Eur J Radiol. 2010; 76:323-28.

32. Wu LM, Gu HY, Zheng J, Xu X, Lin LH, Deng X, Zhang W, Xu JR. Diagnostic value of whole-body magnetic resonance imaging for bone metastases: a systematic review and meta-analysis. J Magn Reson Imaging. 2011; 34:12835 .
33. Messiou C, Collins DJ, Morgan VA, Desouza NM. Optimising diffusion weighted MRI for imaging metastatic and myeloma bone disease and assessing reproducibility. Eur Radiol. 2011; 21:1713-18.

34. Ceci F, Castellucci P, Graziani T, Schiavina R, Chondrogiannis S, Bonfiglioli R, Costa S, Virgolini IJ, Rubello D, Fanti S, Colletti PM. 11C-choline PET/CT identifies osteoblastic and osteolytic lesions in patients with metastatic prostate cancer. Clin Nucl Med. 2015; 40:e26570 .

35. Mürtz P, Krautmacher C, Träber F, Gieseke J, Schild HH, Willinek WA. Diffusion-weighted whole-body MR imaging with background body signal suppression: a feasibility study at 3.0 Tesla. Eur Radiol. 2007; 17:3031-37.

36. Padhani AR, Liu G, Koh DM, Chenevert TL, Thoeny HC, Takahara T, Dzik-Jurasz A, Ross BD, Van Cauteren M, Collins D, Hammoud DA, Rustin GJ, Taouli B, Choyke PL. Diffusion-weighted magnetic resonance imaging as a cancer biomarker: consensus and recommendations. Neoplasia. 2009; 11:102-25.

37. Hara T. 11C-choline and 2-deoxy-2-[18F]fluoro-D-glucose in tumor imaging with positron emission tomography. Mol Imaging Biol. 2002; 4:267-73.

38. Murphy RC, Kawashima A, Peller PJ. The utility of 11C-choline PET/CT for imaging prostate cancer: a pictorial guide. AJR Am J Roentgenol. 2011; 196:1390-98.

39. Svanholm H, Starklint H, Gundersen HJ, Fabricius J, Barlebo H, Olsen S. Reproducibility of histomorphologic diagnoses with special reference to the kappa statistic. APMIS. 1989; 97:689-98. 